\title{
Pharmacokinetic/Pharmacodynamic Interactions Between Evogliptin and Glimepiride in Healthy Male Subjects
}

\author{
Hyounggyoon Yoo (D) \\ Yun Kim (iD \\ In-Jin Jang (1D) \\ Kyung-Sang Yu (DD \\ SeungHwan Lee (iD
}

Department of Clinical Pharmacology and Therapeutics, Seoul National University College of Medicine and Hospital, Seoul, Republic of Korea
Correspondence: SeungHwan Lee Department of Clinical Pharmacology and Therapeutics, Seoul National University College of Medicine and Hospital, I0

Daehak-ro, Jongno-gu, Seoul 03080,

Republic of Korea

Tel +82-2-2072-2343

Fax +82-2-742-9252

Email leejh413@snu.ac.kr
This article was published in the following Dove Press journal: Drug Design, Development and Therapy

Purpose: Evogliptin, a dipeptidyl peptidase- 4 inhibitor, and glimepiride, a sulfonylurea, are used to treat type 2 diabetes mellitus. In this study, we aimed to evaluate the pharmacokinetic (PK) and pharmacodynamic (PD) interactions between evogliptin and glimepiride.

Materials and Methods: A randomized, open-label, 3-period, 3-treatment, 2-sequence crossover study was conducted in healthy male subjects. During each period, subjects received multiple doses of evogliptin $5 \mathrm{mg}$ alone (EVO), glimepiride $4 \mathrm{mg}$ alone (GLI), or a combination of the two $(\mathrm{EVO}+\mathrm{GLI})$. Serial blood and urine samples were collected 168 and $24 \mathrm{~h}$ post dosing, respectively, for PK and PD analyses.

Results: Thirty-four subjects completed the study. The co-administration of evogliptin and glimepiride did not alter their plasma and urine PK profiles. For evogliptin, the geometric mean ratio (GMR) $(90 \%$ confidence intervals) for the maximum plasma concentrations at steady-state $\left(\mathrm{C}_{\text {max,ss }}\right)$ and the area under the curve during dosing interval at steady-state $\left(\mathrm{AUC}_{\tau, \mathrm{ss}}\right)$ of EVO+GLI to E were $1.02(0.98-1.06)$ and $0.97(0.95-1.00)$, respectively. For glimepiride, the corresponding values of EVO+GLI to GLI were 1.08 (1.01-1.17) and 1.08 $(1.02-1.14)$, respectively. All values were within the regulatory bioequivalence criteria of $0.8-1.25$. Glucose excursion decreased with the co-administration of evogliptin and glimepiride compared with that observed with the evogliptin or glimepiride monotherapy.

Conclusion: Evogliptin and glimepiride had no PK interactions when co-administered, while the combination therapy showed an additive glucose-lowering effect compared to those of evogliptin or glimepiride monotherapy.

Keywords: evogliptin, glimepiride, pharmacokinetics, pharmacodynamics, drug interaction

\section{Introduction}

Diabetes mellitus (DM) is a common endocrinological disorder induced by insulin resistance and insulin secretory defect or both. ${ }^{1} \mathrm{DM}$ is one of the main causes of death in adults, which caused four million deaths globally in $2017 .^{1-3}$ Type 2 DM (T2DM) accounts for approximately 90\% of DM. The prevalence of T2DM is rising, which is resulted from ageing, a rapid increase of urbanization and obesogenic environment. ${ }^{2}$

Dipeptidyl peptidase-4 (DPP-4) inhibitors lower blood glucose levels by increasing the levels of active glucagon-like peptide-1 (GLP-1) and glucose-dependent insulinotropic polypeptide (GIP). GLP-1 and GIP increase insulin concentrations in a glucose-dependent fashion by increasing the intracellular levels of cyclic adenosine 3`,5'-monophosphate (cAMP) and lowering glucagon concentrations. ${ }^{4}$ Several 
clinical trials have proven that evogliptin, a DPP-4 inhibitor, has a glucose-lowering effect, resulting in its approval in Korea in 2015. ${ }^{5,6}$ Evogliptin is rapidly absorbed after oral administration and takes approximately $5 \mathrm{~h}$ to reach its maximal plasma concentration $\left(\mathrm{T}_{\max }\right){ }^{7}$ It is mainly eliminated via non-renal routes involving the human cytochrome P450 3A (CYP3A) enzymes. ${ }^{8}$ In particular, 4(S)-hydroxyevogliptin (evogliptin M7) and 4(R)hydroxyevogliptin (evogliptin M8), the main metabolites of evogliptin, are produced by CYP3A4 and CYP3A5, respectively. ${ }^{9}$

Glimepiride is a third-generation sulfonylurea that stimulates insulin release. T2DM is characterized by a predominant insulin secretory defect in Asians, sulfonylureas may be an effective treatment option for them. Therefore, glimepiride has been used as a first-line treatment for T2DM in many countries, including China and Japan. ${ }^{10}$ It is rapidly absorbed after oral administration and reaches its $\mathrm{T}_{\max }$ within $3 \mathrm{~h} .{ }^{11}$ It is mainly eliminated via non-renal routes; this involves $\mathrm{CYP} 2 \mathrm{C} 9$ that metabolizes glimepiride to its main metabolite hydroxyglimepiride (glimepiride M1). ${ }^{11}$

Metformin monotherapy is the recommended first-line pharmacotherapy for T2DM; however, its therapeutic failure is approximately $45 \%$ in Korea. ${ }^{12}$ Many T2DM treatment guidelines recommend combination therapy with drugs that have different mechanisms of action, if monotherapy fails to achieve the glycemic target. ${ }^{13,14}$ Therefore, combination therapy with a DPP-4 inhibitor and sulfonylurea can be an effective T2DM treatment option. Glimepiride has not shown any pharmacokinetic (PK) interactions with DPP-4 inhibitors, including vildagliptin, sitagliptin, and linagliptin. ${ }^{15,16}$ However, its interactions with EVO remain to be evaluated. Therefore, in this study, we aimed to evaluate the PK and pharmacodynamic (PD) interactions between evogliptin and glimepiride.

\section{Materials and Methods}

\section{Subjects}

Healthy Korean male subjects, aged 19-45 years, with a body mass index of $18-27 \mathrm{~kg} / \mathrm{m}^{2}$ were enrolled. They were defined by their previous medical and surgical history, physical examination, vital signs, 12-lead electrocardiography (ECG), and clinical laboratory tests. Subjects who had been exposed to any investigational products within 90 days prior to the first dosing in the study, and those hypersensitive to evogliptin or glimepiride were excluded. All subjects provided a signed informed consent form before any study-related procedure was performed.

\section{Study Design and Procedures}

This was a randomized, open-label, 3-period, 3-treatment, 2-sequence crossover study. It was conducted at Seoul National University Hospital Clinical Trials Center, Seoul, Republic of Korea. The study protocol was reviewed and approved by the Institutional Review Board of Seoul National University Hospital (approval number, H-1607-042-774) and the Korean Ministry of Food and Drug Safety. This study was registered at ClinicalTrials.gov (NCT number, NCT02954822) and conducted in accordance with the major ethical principles of the Declaration of Helsinki and the Korean Good Clinical Practice Guidelines.

Subjects were randomly assigned to sequence A or $\mathrm{B}$ in a $1: 1$ ratio. In sequence $\mathrm{A}, 5 \mathrm{mg}$ of evogliptin (EVO) (evogliptin tartate, Suganon ${ }^{\circledR}$, Seoul, Korea) was orally administered once daily for 1-7 days. Then, $5 \mathrm{mg}$ of evogliptin and $4 \mathrm{mg}$ of glimepiride (EVO+GLI) (glimepiride, Amaryl ${ }^{\circledR}$, Sanofi-Aventis Co. Ltd., France) were orally co-administered once daily on days 8 and 9. Finally, $4 \mathrm{mg}$ of glimepiride (GLI) was orally administered once daily on days 21 and 22 followed by a 12-day wash-out period. In sequence $B$, GLI was orally administered once daily on days 1 and 2, EVO was then orally administered once daily for days 14-20 followed by a 12-day wash-out period. Then, EVO and GLI were orally co-administered once daily on days 21 and 22 (Figure 1).

For the determination of plasma evogliptin, evogliptin M7, and evogliptin M8 concentrations, blood samples $(10 \mathrm{~mL})$ were collected at the following time points: predose samples from days 1-9 and post-dose samples at 1, 2, $3,4,5,6,8$, and $12 \mathrm{~h}$ on days 7 and 9 in sequence $\mathrm{A}$; and pre-dose samples from days 14-22 and post-dose samples at $1,2,3,4,5,6,8$, and $12 \mathrm{~h}$ on days 20 and 22 in sequence B. For the determination of plasma glimepiride and glimepiride M1 concentrations, blood samples were collected at the following time points: pre-dose samples on days $8,9,22$, and 23 , and post-dose samples at $0.5,1,1.5$, $2,3,4,5,6,8$, and $12 \mathrm{~h}$ on days 9 and 22 in sequence $\mathrm{A}$; and pre-dose samples on days $2,3,21$, and 22 , and postdose samples at $0.5,1,1.5,2,3,4,5,6,8$, and $12 \mathrm{~h}$ on days 2 and 22 in sequence $B$ (Figure 1). The blood samples were centrifuged at $1900 \mathrm{~g}$ at $4{ }^{\circ} \mathrm{C}$ for $10 \mathrm{~min}$, and plasma $(4 \mathrm{~mL})$ was transferred into four Eppendorf tubes. For the determination of evogliptin concentration in urine, 


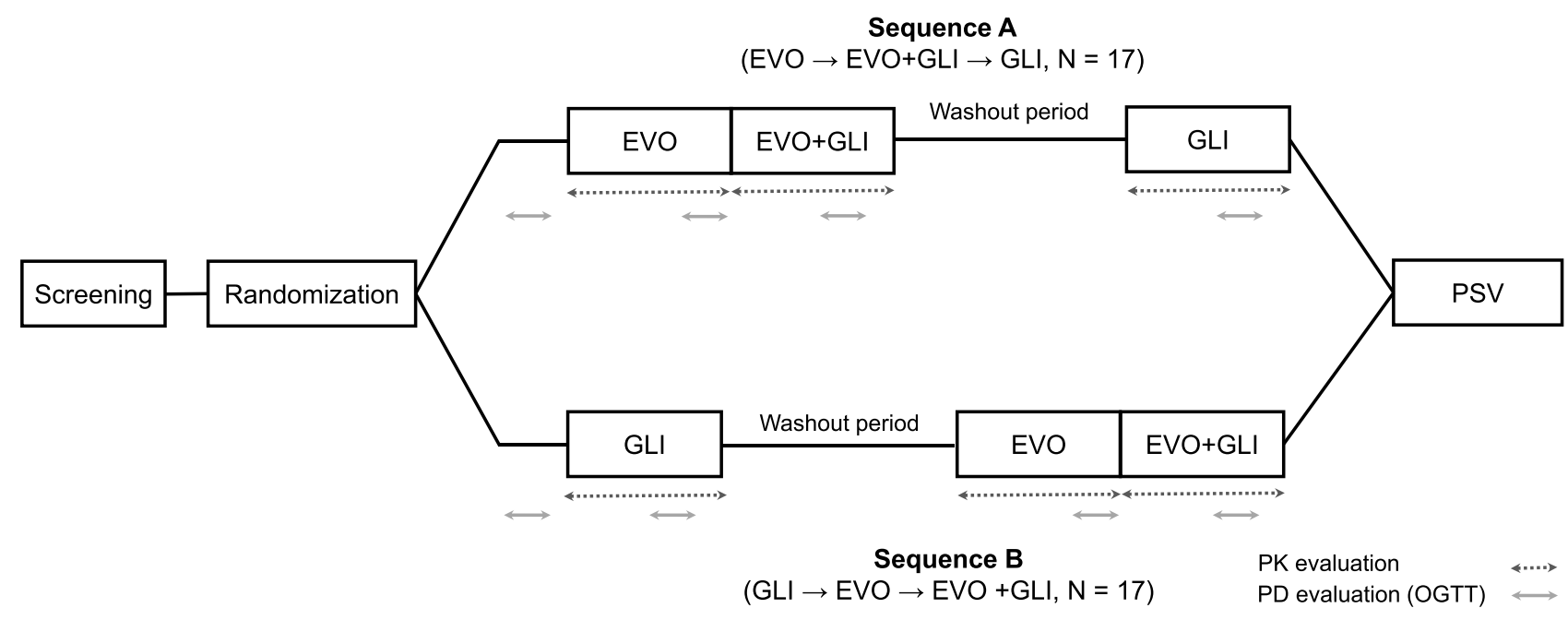

Figure I Study design.

Abbreviations: PK, pharmacokinetics; PD, pharmacodynamics; OGTT, oral glucose tolerance test; EVO, evogliptin 5 mg once daily; GLI, glimepiride 4 mg once daily; EVO +GLI, evogliptin $5 \mathrm{mg}+$ glimepiride $4 \mathrm{mg}$ once daily.

urine samples were collected at the following periods: on days 7,9 , and 22 in sequence $A$, and on days 2,20 , and 22 in sequence $\mathrm{B}$ between 0 and 24 hours. The obtained plasma and urine samples were frozen below $-70^{\circ} \mathrm{C}$ until analysis.

An oral glucose tolerance test (OGTT) was conducted for PD evaluation. After an overnight fast, each subject ingested a test solution containing $75 \mathrm{~g}$ of glucose. Blood samples were collected for the determination of serum glucose and insulin levels at the following time points: 0 , $0.25,0.5,1,1.5,2$, and $3 \mathrm{~h}$ after solution ingestion on days $-1,6,8$, and 21 in sequence $A$ and at the same time points on days $-1,1,19$, and 21 in sequence $B$.

\section{Pharmacokinetic Analysis}

Liquid chromatography with tandem mass spectrometry was used to measure plasma evogliptin, evogliptin M7, evogliptin M8, glimepiride, and glimepiride M1 concentrations as well as urine evogliptin concentration. In blank human plasma and urine samples, no interference from endogenous compounds was observed. The calibration curves of undiluted samples were linear over a range of 0.1 to $60 \mu \mathrm{g} / \mathrm{L}$ for plasma evogliptin, 10 to $10,000 \mathrm{ng} / \mathrm{L}$ for plasma evogliptin M7 and evogliptin M8, 5 to $2000 \mu \mathrm{g} / \mathrm{L}$ for plasma glimepiride, 0.5 to $500 \mu \mathrm{g} / \mathrm{L}$ for plasma glimepiride $\mathrm{M} 1$, and 5 to $50,000 \mu \mathrm{g} / \mathrm{L}$ for urine evogliptin. The within-run accuracy and precision were $97.2-105.5 \%$ and $0.8-7.2 \%$, respectively, for plasma evogliptin, 94.9-103.2\% and $0.2-6.9 \%$, respectively, for plasma evogliptin M7, 86.7-106.3\% and $0.1-11.2 \%$, respectively, for plasma evogliptin M8, plasma glimepiride, and plasma glimepiride M1, and 97.5-104.6\% and $3.3-6.5 \%$, respectively, for urine evogliptin.

The individual PK parameters were determined via noncompartmental methods using Phoenix WinNonlin ${ }^{\circledR}$ software version 8.0 (Certara, Princeton, NJ, USA). The maximum concentration at steady-state $\left(C_{\max , s s}\right)$ and $T_{\max }$ at steady state $\left(\mathrm{T}_{\max , \mathrm{ss}}\right)$ were determined from the plasma concentration-time data. The half-life at steady state $\left(\mathrm{T}_{1 / 2, \mathrm{ss}}\right)$ was determined by fitting a linear regression for evogliptin, evogliptin M7, evogliptin M8, glimepiride, and glimepiride M1. The area under the plasma concentration-time curve over the dosing interval at steady-state $\left(\mathrm{AUC}_{\tau, \mathrm{ss}}\right)$ and the total apparent clearance at steady-state $\left(\mathrm{CL}_{\mathrm{ss}}\right)$ were determined using the linear-log trapezoidal method.

The fraction excreted unchanged in urine over the dosing interval at steady-state $\left(\mathrm{fe}_{\tau, \mathrm{ss}}\right)$ was determined by dividing the amount excreted unchanged in urine over the dosing interval at steady-state $\left(\mathrm{Ae}_{\tau, \mathrm{ss}}\right)$ by the total dose administered on the day of urine collection. Renal clearance at steady-state $\left(\mathrm{CL}_{\mathrm{R}, \mathrm{ss}}\right)$ was determined as $\mathrm{Ae}_{\tau, \mathrm{ss}}$ divided by the $\mathrm{AUC}_{\tau, \mathrm{ss}}$ for evogliptin.

\section{Pharmacodynamic Analysis}

The individual PD parameters at steady-state were determined via noncompartmental methods using Phoenix WinNonlin $^{\circledR}$ software version 8.0 (Certara, Princeton, NJ, USA). The maximum serum glucose $\left(\mathrm{G}_{\max }\right)$ and two-hour postprandial blood glucose ( $2 \mathrm{~h}$ PBG) levels were measured. The area under the glucose-time curve (AUGC) was determined using the linear trapezoidal method. The 
maximum effect $\left(E_{\max }\right)$ and the area under the effect-time curve (AUEC) of insulin were determined using the same method.

The $\Delta \mathrm{G}_{\max }$ and $\Delta \mathrm{E}_{\max }$ were calculated by subtracting the serum glucose and insulin level at each time point in baseline from the serum glucose and insulin level at the corresponding time point, respectively. $\triangle \mathrm{AUGC}$ and $\triangle$ AUEC were calculated by subtracting the serum glucose and insulin level at each time point in baseline from the serum glucose and insulin level at the corresponding time point using the linear trapezoidal method.

\section{Sample Size and Statistical Analysis}

Sample size was determined based on the intra-subject variability of the $C_{\max , s s}$ and $\mathrm{AUC}_{\tau, \mathrm{ss}}$ values for evogliptin and glimepiride reported in previous studies in healthy subjects. A sample size of 32 was selected to detect $20 \%$ differences in the PK parameters while ensuring a statistical power of $80 \%$, with a significance level of $5 \%$. This was done by assuming a maximum intra-subject coefficient of variation for the PK parameters of evogliptin or glimepiride of $33 \% .{ }^{17}$ Considering possible dropouts, 36 subjects were selected as the final sample size.

To evaluate the PK interactions between evogliptin and glimepiride, the geometric mean ratio (GMR) and $90 \%$ confidence interval $(90 \% \mathrm{CI})$ for the $\mathrm{C}_{\mathrm{max}, \mathrm{ss}}$ and $\mathrm{AUC}_{\tau, \mathrm{ss}}$ of the combination therapy compared to those of the monotherapy (EVO+GLI/GLI and EVO+GLI/EVO) were calculated from the analysis of variance model, with the sequence, period, and treatment as fixed effects.

\section{Safety Analysis}

Safety and tolerability were evaluated throughout the study based on adverse events (AEs), physical examinations, vital signs, 12-lead electrocardiogram, and clinical laboratory tests. AEs were observed throughout the study, and the investigators assessed their relationship with the treatments.

\section{Results}

\section{Demographics}

Thirty-six healthy Korean male subjects were enrolled. Their mean age, height, weight, and body mass index were (mean \pm standard deviation) $32.6 \pm 6.1$ years, 173.5 $\pm 5.8 \mathrm{~cm}, 68.5 \pm 7.2 \mathrm{~kg}$, and $22.7 \pm 1.9 \mathrm{~kg} / \mathrm{m}^{2}$, respectively. The demographic characteristics showed no statistically significant differences between the sequences.
One subject withdrew their consent before the first dose, and another subject withdrew during the treatment period. Therefore, 35 subjects were included in the safety assessment, and 34 were included in the PK and PD analyses.

\section{Pharmacokinetics}

For evogliptin, steady-state was achieved on day 4. The mean plasma evogliptin concentration-time curves and PK parameters of EVO and EVO+GLI were similar (Figure 2). The GMR $(90 \% \mathrm{CI})$ of EVO+GLI to EVO for $\mathrm{C}_{\text {max,ss }}$ and $\mathrm{AUC}_{\tau, \mathrm{ss}}$ were $1.02(0.98-1.06)$ and 0.97 (0.95-1.00), respectively (Table 1). The mean plasma EVO M7 and EVO M8 concentration-time curves and PK parameters of EVO M7 and EVO M8 were similar to those of EVO monotherapy and the combination therapy (Table 1, Supplementary Figure 1).

For GLI, the mean plasma GLI concentration-time curves and PK parameters of GLI and the combination therapy were similar (Figure 2). The GMR $(90 \% \mathrm{CI})$ of EVO+GLI to GLI for $\mathrm{C}_{\mathrm{max}, \mathrm{ss}}$ and $\mathrm{AUC}_{\tau, \mathrm{ss}}$ of glimepiride were $1.08(1.01-1.17)$ and $1.08(1.02-1.14)$, respectively (Table 2). Similarly, the mean plasma GLI M1 concentration-time curve PK parameters of GLI M1 were similar to those of GLI monotherapy and the combination therapy (Table 2, Supplementary Figure 1).

\section{Pharmacodynamics}

The serum glucose levels during the OGTT after EVO+GLI were lower than those after EVO or GLI (Figure 3). The $\mathrm{G}_{\max }$ for $\mathrm{EVO}+\mathrm{GLI}$ was lower by 8 and $6.4 \%$ than that for EVO and GLI, respectively. Similar to the $\mathrm{G}_{\max }$, the AUGC for EVO+GLI was lower by 20.4 and $8.6 \%$ than that for EVO and GLI monotherapy, respectively. The $2 \mathrm{~h}$ PBG showed a similar pattern to $\mathrm{G}_{\max }$ and AUGC (Table 3). In addition, the $\Delta \mathrm{G}_{\max }$ and $\triangle \mathrm{AUGC}$ for $\mathrm{EVO}+\mathrm{GLI}$ were lower than those for EVO or GLI (Table 3).

The serum insulin levels after the combination therapy were higher than those after EVO or GLI monotherapy (Figure 3). The $\mathrm{E}_{\max }$ for EVO+GLI was higher by 98.6 and $18.8 \%$ than that for EVO or GLI, respectively. The AUEC for EVO+GLI was also higher by 81.2 and $16.5 \%$ than that for EVO or GLI, respectively (Table 3). In addition, the $\triangle \mathrm{E}_{\max }$ and $\triangle \mathrm{AUEC}$ for $\mathrm{EVO}+\mathrm{GLI}$ were higher than those for EVO or GLI (Table 3).

\section{Safety}

No serious AEs were reported, and no subject discontinued the study owing to AEs. Twenty-four AEs in 10 subjects 

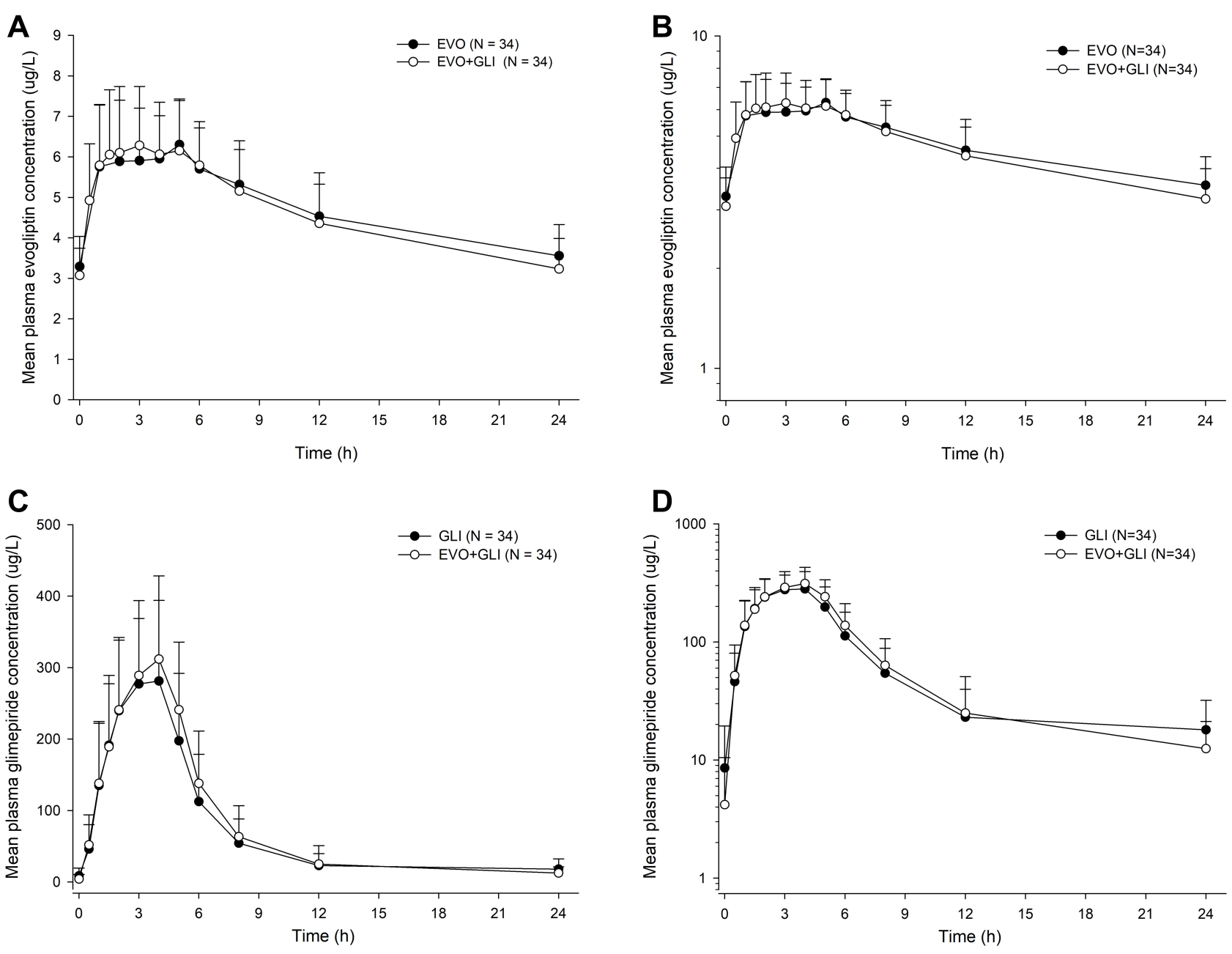

Figure 2 Mean plasma evogliptin and glimepiride concentration-time profiles at steady-state after evogliptin, glimepride, or the combination therapy. Error bars represent the standard deviations. (A) Evogliptin, linear scale, (B) evogliptin, semi-log scale, (C) glimepiride, linear scale, and (D) glimepiride, semi-log scale.

were considered to be related to the investigational products, as follows: one AE (diarrhea) in one subject after EVO, five AEs (increased blood bilirubin, hypoglycemia, nausea, dizziness, and cold sweat) in three subjects after GLI, and 18 AEs, such as abdominal discomfort, asthenia, increased blood bilirubin, cold sweat, dizziness, nausea, throat irritation, in nine subjects after EVO+GLI (Table 4).

In the clinical laboratory tests, no clinically significant changes were observed compared with the baseline values, except for an increase in total bilirubin level in one subject. Furthermore, there were no clinically significant changes in the physical examination, vital signs, and 12lead electrocardiogram.

\section{Discussion}

According to the T2DM treatment guidelines, a combination therapy of DPP-4 inhibitors with sulfonylureas is recommended owing to their different mechanisms of action.
However, clinical use of the evogliptin and glimepiride combination is limited since their potential drug-drug interactions have not been evaluated yet. Therefore, this study is meaningful, as it explored the PK and PD interactions between evogliptin and sulfonylurea in humans.

In drug-drug interaction studies, it is recommended to evaluate the PK interactions at steady-state since it is close to the actual clinical setting, and most of the interactions, including toxicities, occur at steady-state. Therefore, the drugs under investigation need to be administered several times (four or five times depending on the half-life) to reach a steady-state. However, owing to its short half-life (1.2-1.5 h), a single dose of glimepiride was used in this study to reach a steady-state, as previously described. ${ }^{9,18,19}$

For evogliptin, the mean $\mathrm{C}_{\max , \mathrm{ss}}$ and $\mathrm{AUC}_{\tau, \mathrm{ss}}$ were 6.7 $\mu \mathrm{g} / \mathrm{L}$ and $113.1 \mu \mathrm{g} \cdot \mathrm{h} / \mathrm{L}$ in the evogliptin monotherapy and $6.9 \mu \mathrm{g} / \mathrm{L}$ and $110.2 \mu \mathrm{g} \cdot \mathrm{h} / \mathrm{L}$ in the combination therapy, respectively. For glimepiride, the mean $\mathrm{C}_{\max , \mathrm{ss}}$ and 
Table I Pharmacokinetic Parameters of Evogliptin, Evogliptin M7, and Evogliptin M8 at Steady-State After Evogliptin or Evogliptin and Glimepride Combination Therapy

\begin{tabular}{|c|c|c|c|c|}
\hline \multicolumn{2}{|c|}{ Parameters } & \multicolumn{2}{|l|}{ Treatment } & \multirow[t]{2}{*}{$\mathrm{GMR}^{*}(90 \% \mathrm{Cl})$} \\
\hline & & EVO $(N=34)$ & EVO + GLI $(N=34)$ & \\
\hline Evogliptin & $\begin{array}{l}T_{\text {max,ss }} * *(h) \\
C_{\text {trough,ss }}(\mu g / L) \\
C_{\text {max,ss }}(\mu \mathrm{g} / \mathrm{L}) \\
A \cup C_{\tau, s s}(\mu \mathrm{g} \cdot \mathrm{h} / \mathrm{L}) \\
\mathrm{T}_{1 / 2, s s}(\mathrm{~h}) \\
\mathrm{CL}_{s s} / \mathrm{F}(\mathrm{L} / \mathrm{h}) \\
\mathrm{fe}_{\tau, \mathrm{ss}}(\%) \\
\mathrm{CL}_{\mathrm{R}, \mathrm{ss}}(\mathrm{L} / \mathrm{h})\end{array}$ & $\begin{array}{l}4(1.00-6.00) \\
3.3 \pm 0.7(2.2-5.6) \\
6.7 \pm 1.4(4.7-10.3) \\
113.1 \pm 21.6(89.1-188.7) \\
28.4 \pm 8.9(17.1-52.4) \\
45.6 \pm 7.5(26.5-56.1) \\
19.1 \pm 7.2(6.7-43.9) \\
8.4 \pm 2.5(2.8-13.1)\end{array}$ & $\begin{array}{l}3.5(0.5-6.00) \\
3.1 \pm 0.7(2.2-5.1) \\
6.9 \pm 1.5(4.8-10.5) \\
110.2 \pm 21.7(80.2-175.9) \\
23.6 \pm 5.9(15-40.5) \\
46.9 \pm 8.3(28.4-62.4) \\
19.6 \pm 7.6(4.7-48.2) \\
8.9 \pm 2.6(1.8-14.8)\end{array}$ & $\begin{array}{l}1.02(0.98-1.06) \\
0.97(0.95-1.00)\end{array}$ \\
\hline $\begin{array}{l}\text { Evogliptin } \\
\text { M7 }\end{array}$ & $\begin{array}{l}C_{\text {max,ss }}(\mu \mathrm{g} / \mathrm{L}) \\
\operatorname{AUC}_{\tau, \mathrm{ss}}(\mu \mathrm{g} \cdot \mathrm{h} / \mathrm{L}) \\
\mathrm{MR}^{* * * *}\end{array}$ & $\begin{array}{l}0.7 \pm 0.2(0.4-1.2) \\
9.8 \pm 2.4(6.3-14.6) \\
0.09 \pm 0.02(0.03-0.12)\end{array}$ & $\begin{array}{l}0.7 \pm 0.2(0.4-1.0) \\
10.1 \pm 2.8(5.5-17) \\
0.09 \pm 0.02(0.04-0.13)\end{array}$ & $\begin{array}{l}1.06(1.00-1.12) \\
1.03(0.98-1.07)\end{array}$ \\
\hline $\begin{array}{l}\text { Evogliptin } \\
\text { M8 }\end{array}$ & $\begin{array}{l}C_{\text {max }, s s}(\mu \mathrm{g} / \mathrm{L}) \\
\operatorname{AUC}_{\tau, \mathrm{ss}}(\mu \mathrm{g} \cdot \mathrm{h} / \mathrm{L}) \\
M R^{* * * * *}\end{array}$ & $\begin{array}{l}0.6 \pm 0.2(0.4-1.1) \\
10.3 \pm 2.1(6.8-14.7) \\
0.09 \pm 0.02(0.04-0.13)\end{array}$ & $\begin{array}{l}0.6 \pm 0.2(0.3-1) \\
10.4 \pm 2.5(6-17) \\
0.1 \pm 0.02(0.05-0.13)\end{array}$ & $\begin{array}{l}0.99(0.94-1.04) \\
I(0.97-1.04)\end{array}$ \\
\hline
\end{tabular}

Notes: Data are presented as the means \pm standard deviations (minimum-maximum). EVO: evogliptin 5 mg once daily; EVO+GLI: evogliptin 5 mg and glimepiride 4 mg once daily. *Geometric mean ratio (GMR) was calculated as the ratio of the geometric mean of EVO+GLI to that of EVO. **T max is presented as the median (minimummaximum). ****The metabolic ratio (MR) of evogliptin M7 was calculated as the AUC $C_{\tau, s s}$ of evogliptin M7/AUC ${ }_{\tau, s s}$ of evogliptin. ${ }^{* * * *}$ The metabolic ratio (MR) of evogliptin M8 was calculated as the $A \cup C_{\tau, s s}$ of evogliptin $M 8 / A \cup C_{\tau, s s}$ of evogliptin.

Abbreviations: $T_{\max }$, time to reach the peak plasma drug concentration; $C_{\text {trough, }}$, minimum plasma concentration; $C_{\max }$, maximum plasma concentration; $A U C_{\tau}$, area under plasma concentration-time curve over the dosing interval; CL/F, apparent total body clearance following extravascular administration; fe ${ }_{\tau, s s}$, fraction of drug excreted unchanged in urine during the dosing interval at steady-state; $C L_{R, s s}$, renal clearance at steady-state; evogliptin $M 7$, 4(S)-hydroxyevogliptin; and evogliptin $M 8$, $4(R)$ hydroxyevogliptin.

$\mathrm{AUC}_{\tau, \mathrm{ss}}$ were $326.6 \mu \mathrm{g} / \mathrm{L}$ and $1672.7 \mu \mathrm{g} \cdot \mathrm{h} / \mathrm{L}$ in the glimepiride monotherapy and $350.9 \mu \mathrm{g} / \mathrm{L}$ and $1794.9 \mu \mathrm{g} \cdot \mathrm{h} / \mathrm{L}$ in the combination therapy, respectively. The $90 \% \mathrm{CIs}$ of GMR of the combination therapy to the evogliptin or glimepiride monotherapy for all of these parameters were within the $\mathrm{PK}$ equivalence range of $80 \%$ to $125 \%$. Therefore, this study revealed that evogliptin and glimepiride exhibited no significant PK interactions. In addition,

Table 2 Pharmacokinetic Parameters of Glimepiride and Glimepiride MI at Steady-State After Glimepride or the Combination Therapy

\begin{tabular}{|c|c|c|c|c|}
\hline \multicolumn{2}{|l|}{ Parameters } & \multicolumn{2}{|l|}{ Treatment } & \multirow[t]{2}{*}{ GMR* $(90 \% \mathrm{Cl})$} \\
\hline & & GLI $(\mathbf{N}=34)$ & EVO + GLI $(N=34)$ & \\
\hline Glimepiride & $\begin{array}{l}\mathrm{T}_{\text {max }, \mathrm{ss}} * *(\mathrm{~h}) \\
\mathrm{C}_{\text {trough,ss }}(\mu \mathrm{g} / \mathrm{L}) \\
\mathrm{C}_{\max , \mathrm{ss}}(\mu \mathrm{g} / \mathrm{L}) \\
\mathrm{AUC}_{\tau, \mathrm{ss}}(\mu \mathrm{g} \cdot \mathrm{h} / \mathrm{L}) \\
\mathrm{T}_{1 / 2, \mathrm{ss}}(\mathrm{h}) \\
\mathrm{CL}_{s \mathrm{~s}} / \mathrm{F}(\mathrm{L} / \mathrm{h})\end{array}$ & $\begin{array}{l}3(1.5-5) \\
8.6 \pm 10.9(0-51.9) \\
326.6 \pm 98.5(143.8-562.9) \\
1672.7 \pm 623.9(783.9-3293.8) \\
4.7 \pm 2.2(1.7-4.2) \\
2.7 \pm 1(1.2-5.1)\end{array}$ & $\begin{array}{l}4(1-6) \\
4.2 \pm 6.3(0-24.7) \\
350.9 \pm 97.4(185.1-547.8) \\
1794.9 \pm 653.2(883.6-3282.8) \\
4.2 \pm 2(1.7-8.4) \\
2.5 \pm 0.8(1.2-4.5)\end{array}$ & $\begin{array}{l}1.08(1.01-1.17) \\
1.08(1.02-1.14)\end{array}$ \\
\hline Glimepiride MI & $\begin{array}{l}C_{\text {max }, s s}(\mu g / L) \\
\operatorname{AUC}_{\tau, \text { ss }}(\mu g \cdot h / L) \\
M R^{* * * *}\end{array}$ & $\begin{array}{l}81.3 \pm 20.6(47.7-135.3) \\
611.9 \pm 180.7(309.4-1179.5) \\
0.4 \pm 0.11(0.2-0.63)\end{array}$ & $\begin{array}{l}84.2 \pm 19(55.8-137) \\
652.6 \pm 197.7(387-1331.4) \\
0.39 \pm 0.1(0.19-0.62)\end{array}$ & $\begin{array}{l}1.05(0.98-1.11) \\
1.07(1.02-1.12)\end{array}$ \\
\hline
\end{tabular}

Notes: Data are presented as the means \pm standard deviations (minimum-maximum). *Geometric mean ratio (GMR) was calculated as the ratio of the geometric mean of EVO+GLI to that of GLI. ${ }^{* *} \mathrm{~T}_{\max }$ is presented as the median (minimum-maximum). ${ }^{* * *}$ The metabolic ratio (MR) of glimepiride MI was calculated as the AUC ${ }_{\tau, s s}$ of glimepiride MI/AUC ${ }_{\tau, s s}$ of glimepiride. GLI: glimepiride $4 \mathrm{mg}$ once daily; EVO+GLI, evogliptin $5 \mathrm{mg}$ and glimepiride $4 \mathrm{mg}$ once daily.

Abbreviations: ${ }_{\max }$, time to reach the peak plasma drug concentration; $\mathrm{C}_{\text {trough }}$, minimum plasma concentration; $\mathrm{C}_{\text {max }}$, maximum plasma concentration; $A \mathrm{C}_{\tau}$, area under plasma concentration-time curve over the dosing interval; CL/F, apparent total body clearance following extravascular administration; and glimepiride MI, hydroxylglimepiride. 

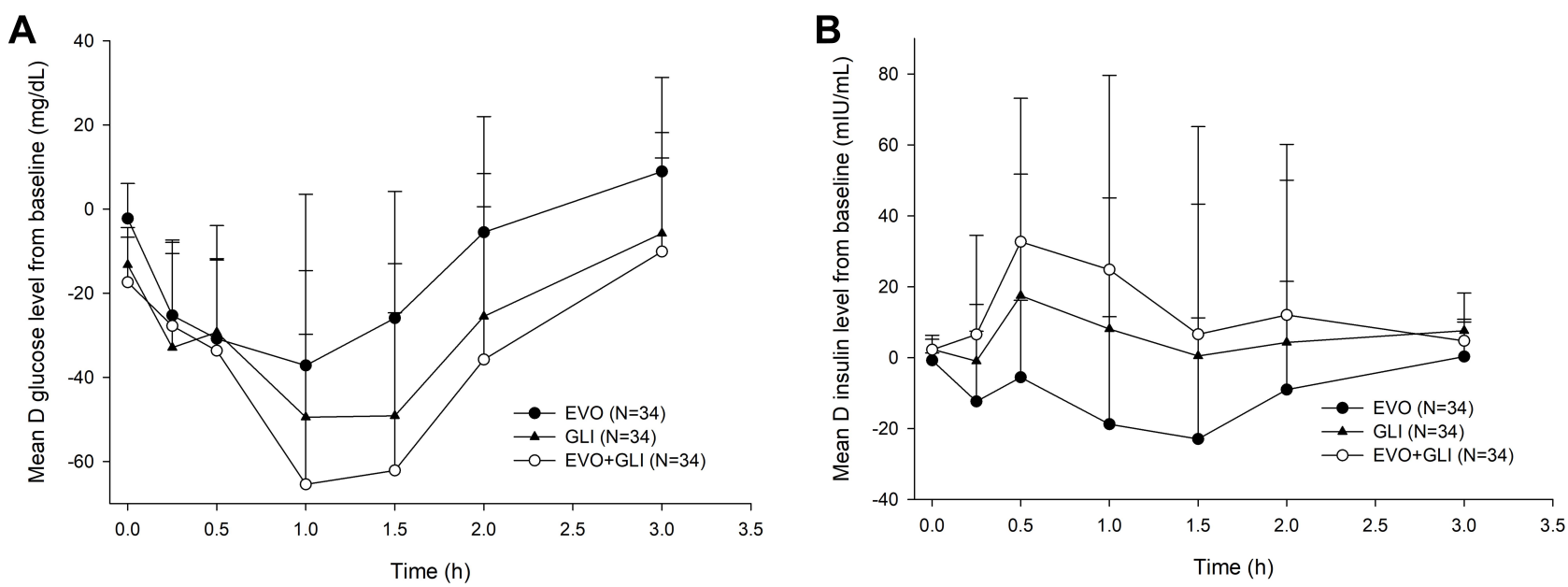

Figure 3 Mean $\Delta$ serum glucose $(\mathbf{A})$ and $\Delta$ serum insulin (B) level-time profiles at steady-state after evogliptin, glimepride, or the combination therapy. The $\Delta$ glucose and $\Delta$ insulin were calculated by subtracting the values at $0 \mathrm{~h}$ from the values at each time point. Error bars represent the standard deviations.

these results were similar to those of studies that evaluated PK interactions between glimepiride and other DPP-4 inhibitors including teneligliptin and gemigliptin. ${ }^{20,21}$

Evogliptin is mainly metabolized by CYP3A, whereas glimepiride might be a potential CYP3A4 inhibitor as evinced from the increased plasma concentration of sildenafil that is mainly metabolized by CYP3A4 in rats. ${ }^{8,22}$ Additionally, evogliptin did not significantly change the PK properties of glimepiride that is mainly metabolized by CYP2C9, ie, evogliptin did not induce or inhibit CYP enzymes (unpublished in-house data). In addition, evogliptin and glimepiride did not affect the formation of each major metabolite.

As expected, the combination therapy showed additive glycemic control $\left(\mathrm{G}_{\max } 125.8 \mathrm{mg} / \mathrm{dL}\right.$, AUGC $266.6 \mathrm{mg} \cdot \mathrm{h} /$ $\mathrm{dL})$ compared to evogliptin $\left(\mathrm{G}_{\max } 136.7 \mathrm{mg} / \mathrm{dL}\right.$, AUGC $334.9 \mathrm{mg} \cdot \mathrm{h} / \mathrm{dL})$ or glimepiride monotherapy $\left(\mathrm{G}_{\max }\right.$ $134.4 \mathrm{mg} / \mathrm{dL}$, AUGC $291.8 \mathrm{mg} \cdot \mathrm{h} / \mathrm{dL}$ ). However, the strength of the additive effect observed in this study was weaker than expected, and it might be attributed to the

Table 3 Pharmacodynamic Parameters for Serum Glucose and Insulin Levels During an Oral Glucose Tolerance Test at Steady-State After Evogliptin, Glimepride, or the Combination Therapy

\begin{tabular}{|c|c|c|c|c|c|}
\hline \multicolumn{2}{|l|}{ Parameters } & \multicolumn{4}{|l|}{ Treatment } \\
\hline & & Baseline $(\mathbf{N}=34)$ & EVO $(N=34)$ & GLI (N = 34) & EVO + GLI $(N=34)$ \\
\hline $\begin{array}{l}\text { Serum } \\
\text { Glucose }\end{array}$ & $\begin{array}{l}\mathrm{G}_{\max }(\mathrm{mg} / \mathrm{dL}) \\
\Delta \mathrm{G}_{\max }(\mathrm{mg} / \mathrm{dL}) \\
A \cup G C(\mathrm{mg} \cdot \mathrm{h} / \mathrm{dL}) \\
\triangle A U G C(\mathrm{mg} \cdot \mathrm{h} / \mathrm{dL}) \\
2 \text { h PBG }(\mathrm{mg} / \mathrm{dL})\end{array}$ & $\begin{array}{l}175.5 \pm 33.5(137-267) \\
- \\
384 \pm 65.9 \\
(267.1-589.9) \\
- \\
120.2 \pm 33.9(68-248)\end{array}$ & $\begin{array}{l}136.7 \pm 14.4(113-173) \\
-53.2 \pm 32(-162--12) \\
334.9 \pm 31.7(260-406.5) \\
-35.8 \pm 39.2 \\
(-137.6-18.5) \\
\mid 14.7 \pm 17.3(83-164)\end{array}$ & $\begin{array}{l}134.4 \pm 26.9(95-207) \\
-68.9 \pm 25.1(-129--22) \\
291.8 \pm 48.5 \\
(216.1-429.6) \\
-67.5 \pm 60(-179.6-69.4) \\
94.7 \pm 23.9(44-140)\end{array}$ & $\begin{array}{l}125.8 \pm 15(10.1-165) \\
-80.2 \pm 32.3(-149--31) \\
266.6 \pm 31.8 \\
(203.5-343.1) \\
-68.2 \pm 51.4(-155.7-2.5) \\
84.4 \pm 19.6(44-124)\end{array}$ \\
\hline Serum Insulin & $\begin{array}{l}\mathrm{E}_{\max }(\mu \mathrm{lU} / \mathrm{mL}) \\
\Delta \mathrm{E}_{\max }(\mu \mathrm{lU} / \mathrm{mL}) \\
\text { AUEC }(\mu \mathrm{IU} \cdot \mathrm{h} / \mathrm{mL}) \\
\Delta \text { AUEC }(\mu \mathrm{IU} \cdot \mathrm{h} / \mathrm{mL})\end{array}$ & $\begin{array}{l}73.5 \pm 48.6(20-206.8) \\
- \\
123.9 \pm 76.5(31-368.4) \\
-\end{array}$ & $\begin{array}{l}53.1 \pm 25.2(16.3-124.2) \\
-20.4 \pm 35.5 \\
(-142.5-21.7) \\
91.1 \pm 48.6(31.4-265) \\
-19.2 \pm 46.6 \\
(-179.9-36.1)\end{array}$ & $\begin{array}{l}86.4 \pm 43.8(29.7-248.4) \\
12.9 \pm 45.2 \\
(-109.2-122.1) \\
141.7 \pm 65.5(40.7-318.2) \\
17.9 \pm 60.1 \\
(-174.5-157.2)\end{array}$ & $\begin{array}{l}105.5 \pm 66.8(25.4-352.4) \\
32 \pm 48.7(-67.5-206.1) \\
165.1 \pm 106(47.7-571.3) \\
41.5 \pm 78.2(-78.5-384.7)\end{array}$ \\
\hline
\end{tabular}

Notes: Data are presented as the means \pm standard deviations (minimum-maximum). EVO: evogliptin $5 \mathrm{mg}$ once daily; GLI: glimepiride $4 \mathrm{mg}$ once daily; and EVO+GLI, evogliptin $5 \mathrm{mg}$ and glimepiride $4 \mathrm{mg}$ once daily.

Abbreviations: $\mathrm{G}_{\max }$, maximum serum glucose level; $\Delta \mathrm{G}_{\max }$, difference in maximum serum glucose level from baseline; AUGC, area under the serum glucose-time curve; $\triangle A U G C$, difference in the area under the serum glucose-time curve from baseline; $2 \mathrm{~h} \mathrm{PBG,} 2$ hour postprandial blood glucose; $E_{\max }$, maximum serum insulin level; $\triangle E_{\max }$, difference in maximum serum insulin level from baseline; AUEC, area under the serum insulin-time curve; $\triangle A U E C$, difference in the area under the serum insulin-time curve from baseline; and AUEC, area under the serum insulin-time curve. 
Table 4 Adverse Drug Reactions Following Evogliptin, Glimepride, or the Combination Therapy

\begin{tabular}{|l|l|l|l|}
\hline \multicolumn{2}{|l|}{ Treatment } \\
\cline { 2 - 4 } & $\begin{array}{l}\text { EVO } \\
\mathbf{( N = 3 5 )}\end{array}$ & $\begin{array}{l}\text { GLI } \\
\text { (N = 35) }\end{array}$ & $\begin{array}{l}\text { EVO + GLI } \\
\text { (N = 35) }\end{array}$ \\
\hline Diarrhea & I (I) & & \\
Abdominal discomfort & & & I (I) \\
Nausea & & I (I) & I (I) \\
Asthenia & & & $3(3)$ \\
Increased blood bilirubin & & I (I) & I (I) \\
Hypoglycemia & & I (I) & $5(5)$ \\
Dizziness & & I (I) & I (I) \\
Throat irritation & & I (I) & $5(6)$ \\
Cold sweat & & & \\
\hline
\end{tabular}

Notes: Data are presented as the number of subjects who reported adverse drug reactions (the number of ADRs). EVO, evogliptin $5 \mathrm{mg}$ once daily; GLI, glimepiride $4 \mathrm{mg}$ once daily; and EVO+GLI, evogliptin $5 \mathrm{mg}$ and glimepiride $4 \mathrm{mg}$ once daily.

differences in glycemic homeostasis between healthy subjects and T2DM patients. For example, GLP-1 did not augment insulin-mediated glucose uptake in young healthy subjects with euglycemia. ${ }^{23}$

Although DPP-4 inhibitors increased postprandial insulin secretion, evogliptin monotherapy decreased insulin secretion in healthy subjects. ${ }^{24,25}$ This effect was also observed in previous studies in healthy volunteers. $^{6,26,27}$ Although the mechanism is not known, differences between healthy subjects and T2DM patients, such as different blood glucagon levels, might explain this finding. ${ }^{28}$ Therefore, further studies are needed to evaluate the PD interactions in T2DM patients.

There were more AEs for the combination therapy compared to glimepiride monotherapy. The increased AEs including dizziness, asthenia, and cold sweat in this study were hypoglycemic symptoms. Glimepiride is well known to result in hypoglycemia; therefore, it is considered that the increased AEs were resulted from improved glycemic control by combination therapy. ${ }^{18}$ Further studies including T2DM patients are needed to confirm the safety of the combination therapy.

This study has a limitation. This study was performed in healthy subjects to minimize confounding factors that could affect the study results. Therefore, the PK, PD, and safety profiles of T2DM patients may be different from the results of this study. Further studies including T2DM patients are needed to confirm the PK, PD, and safety profiles of the combination therapy.

\section{Conclusion}

In conclusion, co-administration of evogliptin and glimepiride did not result in PK interactions; however, they showed an additive glucose-lowering effect. Therefore, evogliptin and glimepiride combination therapy might be an alternative treatment option for T2DM patients who have inadequate glycemic control with DPP-4 inhibitors or sulfonylurea monotherapy.

\section{Data Sharing Statements}

The data that support the findings of this study are available from the corresponding investigator upon reasonable request.

\section{Acknowledgments}

This study was sponsored by Dong-A ST Co., Ltd., Seoul, Republic of Korea.

\section{Disclosure}

The authors have no competing interests to declare.

\section{References}

1. Mishra MK. Medicinal plants: role in treatment of diabetes. Int $J$ Adv Sci Res Manag. 2019;S1:139-153.

2. Saeedi P, Petersohn I, Salpea P, et al. Global and regional diabetes prevalence estimates for 2019 and projections for 2030 and 2045: results from the International Diabetes Federation Diabetes Atlas. Diabetes Res Clin Pract. 2019;157:107843. doi:10.1016/j. diabres.2019.107843

3. Shah MA, Jakkawanpitak C, Sermwittayawong D, Panichayupakaranant P. Rhinacanthins-rich extract enhances glucose uptake and inhibits adipogenesis in 3T3-L1 adipocytes and L6 myotubes. Pharmacogn Mag. 2017;13(Suppl 4):S817.

4. Ahren B. DPP-4 inhibitors. Best Pract Res Clin Endocrinol Metab. 2007;21(4):517-533. doi:10.1016/j.beem.2007.07.005

5. Hong SM, Park CY, Hwang DM, et al. Efficacy and safety of adding evogliptin versus sitagliptin for metformin-treated patients with type 2 diabetes: a 24-week randomized, controlled trial with open label extension. Diabetes Obes Metab. 2017;19(5):654-663.

6. Park J, Park SW, Yoon KH, et al. Efficacy and safety of evogliptin monotherapy in patients with type 2 diabetes and moderately elevated glycated haemoglobin levels after diet and exercise. Diabetes Obes Metab. 2017;19(12):1681-1687. doi:10.1111/dom.12987

7. Gu N, Park MK, Kim TE, et al. Multiple-dose pharmacokinetics and pharmacodynamics of evogliptin (DA-1229), a novel dipeptidyl peptidase IV inhibitor, in healthy volunteers. Drug Des Devel Ther. 2014;8:1709-1721. doi:10.2147/DDDT.S65678

8. Kim HJ, Kwak WY, Min JP, et al. Discovery of DA-1229: a potent, long acting dipeptidyl peptidase-4 inhibitor for the treatment of type 2 diabetes. Bioorg Med Chem Lett. 2011;21(12):3809-3812. doi:10.1016/j.bmcl.2011.04.029

9. Oh E, Choi C, Kim C, et al. Effects of clarithromycin on the pharmacokinetics of evogliptin in healthy volunteers. J Clin Pharm Ther. 2017;42(6):689-694. doi:10.1111/jcpt.12604

10. Chan JC, Malik V, Jia W, et al. Diabetes in Asia: epidemiology, risk factors, and pathophysiology. JAMA. 2009;301(20):2129-2140. doi:10.1001/jama.2009.726 
11. Langtry HD, Balfour JA. Glimepiride. Drugs. 1998;55(4):563-587. doi:10.2165/00003495-199855040-00007

12. Hotta N. A new perspective on the biguanide, metformin therapy in type 2 diabetes and lactic acidosis. J Diabetes Investig. 2019;10 (4):906-908. doi:10.1111/jdi.13090

13. Ko S-H, Hur K-Y, Rhee SY, et al. Antihyperglycemic agent therapy for adult patients with type 2 diabetes mellitus 2017: a position statement of the Korean Diabetes Association. Diabetes Metab J. 2017;41(5):337-348. doi:10.4093/dmj.2017.41.5.337

14. McGuire H, Longson D, Adler A, Farmer A, Lewin I. Management of type 2 diabetes in adults: summary of updated NICE guidance. BMJ. 2016;353:i1575. doi:10.1136/bmj.i1575

15. Serra D, He Y, Bullock J, et al. Evaluation of pharmacokinetic and pharmacodynamic interaction between the dipeptidyl peptidase IV inhibitor vildagliptin, glyburide and pioglitazone in patients with Type 2 diabetes. Int J Clin Pharmacol Ther. 2008;46(7):349-364. doi:10.5414/CPP46349

16. Friedrich C, Metzmann K, Rose P, Mattheus M, Pinnetti S, Woerle HJ. A randomized, open-label, crossover study to evaluate the pharmacokinetics of empagliflozin and linagliptin after coadministration in healthy male volunteers. Clin Ther. 2013;35(1):A33A42. doi:10.1016/j.clinthera.2012.12.002

17. Karim A, Zhao Z, Slater M, Bradford D, Schuster J, Laurent A. Replicate study design in bioequivalency assessment, pros and cons: bioavailabilities of the antidiabetic drugs pioglitazone and glimepiride present in a fixed-dose combination formulation. $J$ Clin Pharmacol. 2007;47(7):806-816. doi:10.1177/0091270007300954

18. Niemi M, Backman JT, Neuvonen M, Laitila J, Neuvonen PJ, Kivistö KT. Effects of fluconazole and fluvoxamine on the pharmacokinetics and pharmacodynamics of glimepiride. Clin Pharmacol Ther. 2001;69(4):194-200. doi:10.1067/mcp.2001.114229

19. Macha S, Mattheus M, Pinnetti S, Seman L, Woerle HJ. Pharmacokinetics of empagliflozin, a sodium glucose cotransporter 2 inhibitor, and glimepiride following co-administration in healthy volunteers: a randomised, open-label, crossover study. J Diabetes Res Clin Metab. 2012;1(1):14. doi:10.7243/2050-0866-1-14

20. Park JW, Kim KA, Choi YJ, Yoon SH, Park JY. Effect of glimepiride on the pharmacokinetics of teneligliptin in healthy Korean subjects. J Clin Pharm Ther. 2019;44(5):720-725. doi:10.1111/jept.12848
21. Choi HY, Kim YH, Kim MJ, et al. Evaluation of pharmacokinetic drug interactions between gemigliptin (dipeptidylpeptidase-4 inhibitor) and glimepiride (sulfonylurea) in healthy volunteers. Drugs $R D$. 2014;14(3):165-176. doi:10.1007/s40268-014-0054-8

22. Tripathi AS, Timiri AK, Mazumder PM, Chandewar A. Does glimepiride alter the pharmacokinetics of sildenafil citrate in diabetic nephropathy animals: investigating mechanism of interaction by molecular modeling studies. J Mol Model. 2015;21(10):276. doi:10.1007/s00894-015-2823-x

23. Ryan AS, Egan JM, Habener JF, Elahi D. Insulinotropic hormone glucagon-like peptide-1-(7-37) appears not to augment insulinmediated glucose uptake in young men during euglycemia. $J$ Clin Endocrinol Metab. 1998;83(7):2399-2404.

24. Nauck MA, Heimesaat MM, Orskov C, Holst JJ, Ebert R, Creutzfeldt W. Preserved incretin activity of glucagon-like peptide 1 [7-36 amide] but not of synthetic human gastric inhibitory polypeptide in patients with type-2 diabetes mellitus. J Clin Invest. 1993;91(1):301-307. doi:10.1172/JCI116186

25. Holst JJ, Gromada J. Role of incretin hormones in the regulation of insulin secretion in diabetic and nondiabetic humans. Am J Physiol Endocrinol Metab. 2004;287(2):E199-E206. doi:10.1152/ajpendo. 00545.2003

26. Jung $\mathrm{CH}$, Park CY, Ahn KJ, et al. A randomized, double-blind, placebo-controlled, Phase II clinical trial to investigate the efficacy and safety of oral DA-1229 in patients with type 2 diabetes mellitus who have inadequate glycaemic control with diet and exercise. Diabetes Metab Res Rev. 2015;31(3):295-306. doi:10.1002/ dmrr.2613

27. Rhee SJ, Choi Y, Lee S, et al. Pharmacokinetic and pharmacodynamic interactions between metformin and a novel dipeptidyl peptidase-4 inhibitor, evogliptin, in healthy subjects. Drug Des Devel Ther. 2016;10:2525-2534. doi:10.2147/DDDT.S110712

28. Dunning B, Foley J, Ahrén B. Alpha cell function in health and disease: influence of glucagon-like peptide-1. Diabetologia. 2005;48 (9):1700-1713. doi:10.1007/s00125-005-1878-0
Drug Design, Development and Therapy

\section{Publish your work in this journal}

Drug Design, Development and Therapy is an international, peerreviewed open-access journal that spans the spectrum of drug design and development through to clinical applications. Clinical outcomes, patient safety, and programs for the development and effective, safe, and sustained use of medicines are a feature of the journal, which has also been accepted for indexing on PubMed Central. The manuscript management system is completely online and includes a very quick and fair peer-review system, which is all easy to use. Visit http://www. dovepress.com/testimonials.php to read real quotes from published authors. 